Arq. Bras. Med. Vet. Zootec., v.71, n.1, p.340-344, 2019

\title{
Comunicação
}

[Communication]

\section{Aspectos morfológicos do rúmen, omaso e fígado de tourinhos alimentados com diferentes níveis de glicerina bruta}

\author{
[Morphological aspects of rumen, omasum and liver of bulls fed different levels of crude glycerin] \\ S.F. Costa, L.Q. Melo, M. Resende Neto, J.R.R. Carvalho, \\ M.M. Ladeira, M.G. Zangeronimo \\ Universidade Federal de Lavras - UFLA - Lavras, MG
}

\begin{abstract}
A glicerina bruta (GB) é o principal coproduto da produção do biodiesel. Com a crescente produção de biodiesel no Brasil, têm-se gerado grandes estoques desse coproduto, o que gera a necessidade de seu uso. Considerando que a GB pode ser utilizada em dietas como fonte de energia, substituindo o milho, e que o custo com a alimentação animal pode representar $70 \%$ do custo de produção, o uso desse coproduto na alimentação de bovinos de corte pode ser uma alternativa plausível não só para reduzir os custos com a alimentação, mas também para contribuir com a sustentabilidade da produção de biodiesel (Ladeira et al., 2016). O grande interesse na utilização da GB em dietas de ruminantes é devido ao elevado teor de glicerol. Nos ruminantes, o glicerol presente na GB pode ser rapidamente fermentado no rúmen e acarretar maior produção de propionato e butirato (Van Cleef et al., 2015; Defrain et al., 2004), ou ser absorvido pela mucosa ruminal e convertido à glicose no fígado (Krehbiel, 2008). Após chegar ao fígado, tanto o glicerol como o propionato serão transformados em glicose por gliconeogênese. Pesquisas demonstram o potencial de utilização da GB na dieta de bovinos e têm sido realizadas com o intuito de avaliar o comportamento ingestivo, o desempenho, a característica de carcaça, a qualidade da carne e o custo de produção (Ladeira et al., 2016; Paschoaloto, 2016; Donkin, 2008). Entretanto, são escassos os estudos objetivando avaliar os parâmetros morfopatológicos da mucosa da parte aglandular do estômago e do fígado de bovinos alimentados com GB (Paschoaloto, 2016).
\end{abstract}

A mucosa ruminal pode responder a diferentes padrões alimentares. O tipo de ácido graxo de cadeia curta (AGCC) presente no conteúdo ruminal pode afetar a resposta em crescimento das células epiteliais. Alteração da taxa de divisão celular é uma das principais características de adaptação do epitélio ruminal e, consequentemente, certos componentes da dieta apresentam uma apreciável influência sobre essa taxa. Propionato e butirato parecem ser mais estimuladores do crescimento papilar que o acetato (Costa et al., 2008). Considerando que a fermentação de glicerol pode acarretar maior produção de propionato e butirato e, consequentemente, induzir maior proliferação celular no epitélio ruminal, a utilização de GB na dieta de bovinos refletirá em maior número e dimensões papilares e superfície absortiva ruminal. De acordo com Krehbiel (2008), aproximadamente $13 \%$ do glicerol que chega ao rúmen desaparece por passagem com a digesta, $44 \%$ por fermentação e $43 \%$ por absorção pela parede ruminal. A capacidade de absorção do rúmen responde, positivamente, a estímulos diretos e indiretos dos AGCC e há evidências de que a mucosa omasal também responde a esses estímulos. Existe pouca informação sobre a resposta morfológica da mucosa omasal a dietas ricas em carboidrato, mesmo sabendo-se que esse órgão recebe de $36 \%$ a $45 \%$ de AGCC produzido no rúmen (Resende Júnior et al., 2006). Considerando que $13 \%$ do glicerol que chega ao rúmen desaparece por passagem com a digesta (Krehbiel, 2008), a extensão da superfície absortiva do omaso pode desempenhar um papel importante tanto no clearance de AGCC como no de glicerol.

Recebido em 18 de abril de 2017 
Por serem escassos os estudos avaliando os parâmetros morfopatológicos do estômago e do fígado de bovinos alimentados com GB, este trabalho objetivou avaliar a resposta morfológica da mucosa do rúmen e do omaso e do parênquima hepático de tourinhos terminados em confinamento e alimentados com diferentes níveis de GB na matéria seca da dieta.

Os procedimentos envolvendo animais foram executados anteriormente por Ladeira et al. (2016). Todos os procedimentos foram aprovados pela Comissão de Ética no Uso Animais da Universidade Federal de Lavras. Foram utilizados 44 novilhos da raça Nelore em um delineamento inteiramente ao acaso. As dietas totais tiveram a silagem de milho como volumoso, e quatro diferentes tipos de concentrados foram utilizados, variando o nível de inclusão de GB $(0,6,12$ e $18 \%)$, tendo esta substituído o milho integral moído (Ladeira et al., 2016) (Tab. 1).

Após as etapas de abate, coletou-se um fragmento de aproximadamente $5 \mathrm{~cm}^{2}$ de cada animal na porção cranial do saco ventral (recesso) do rúmen, o qual foi mantido em solução tampão fosfato para análise macroscópica (Daniel et al., 2006). Fragmentos de aproximadamente $2 \mathrm{~cm}^{2}$ da mesma região do rúmen, do omaso e do fígado foram coletados e fixados em solução de Bouin. Posteriormente, as amostras foram processadas rotineiramente para inclusão em parafina, e os cortes teciduais corados em hematoxilina-eosina - HE (Costa $e t$ al., 2008). As variáveis macroscópicas avaliadas no rúmen foram: 1 - número de papilas por $\mathrm{cm}^{2}$ de parede; 2- área das papilas e da superfície total de absorção por $\mathrm{cm}^{2}$ de parede. A área da superfície absortiva ruminal foi mensurada em imagens digitalizadas das papilas e da superfície parietal dos fragmentos (programa de análise de imagens UTHSCSA Image Tool, software livre) e estimada pelas equações de regressão propostas por Daniel et al. (2006). As variáveis microscópicas avaliadas no rúmen e no omaso foram: 1- índice mitótico; 2- altura e área papilar, utilizando-se o programa de análises morfométricas Cell B (Olympus) (Azevedo et al., 2016). A avaliação microscópica hepática considerou a possível presença de lesões, classificando-as de acordo com o grau das lesões em escores de zero a três ( 0 - ausente; 1 - leve; 2 - moderada; 3 - acentuada).

Tabela 1. Composição das dietas oferecidas em ingredientes e das dietas consumidas em nutrientes $(\mathrm{g} / \mathrm{kg})$

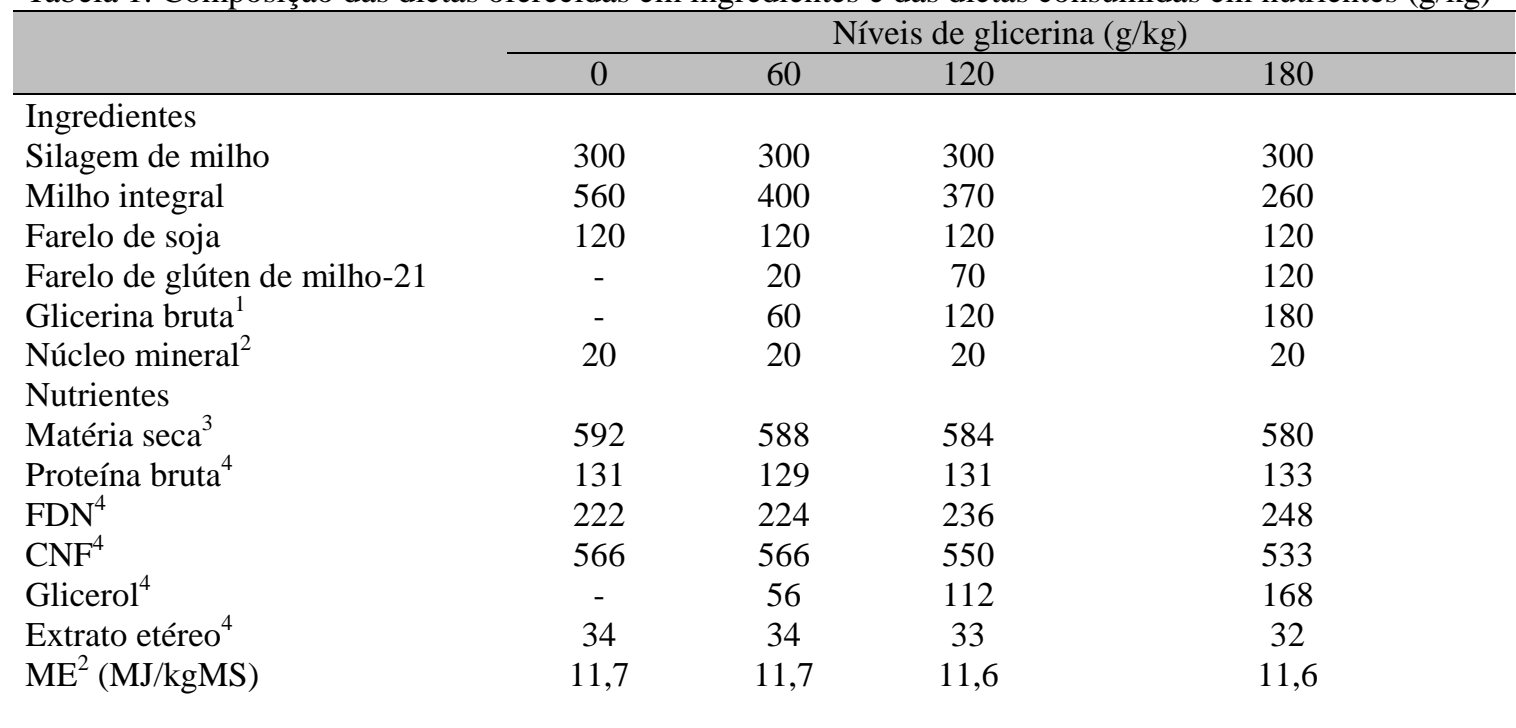

\footnotetext{
${ }^{1}$ Níveis garantidos por quilograma de produto: glicerol: 831 ; umidade: 111 ; cinzas: 60,6 ; cloretos: 36,7; metanol: 0,2.

${ }^{2}$ Níveis garantidos por quilograma de produto: Ca: $170 \mathrm{~g}$; Na: 155g; P: 31g; Zn: 2mg; Cu: 396mg; Mn: 515mg; Co: 15mg; I: 29mg; Se: 5,4mg; vitamina A: 111.000UI; vitamina D3: 22.000UI; vitamina E: 265UI.

${ }^{3} \mathrm{Com}$ base na matéria natural.

${ }^{4} \mathrm{Com}$ base na matéria seca.
} 
Os dados morfológicos macroscópicos e microscópicos foram analisados utilizando-se o pacote estatístico Action 3.1. Inicialmente, os dados foram submetidos ao teste de normalidade (Shapiro-Wilk) e homocedasticidade das variâncias (Breusch-Pagan). Em seguida, foram submetidos à análise de variância, e os níveis de glicerina à análise de regressão. Cada teor de glicerina também foi comparado ao controle (sem glicerina) pelo teste de Dunnett a 5\%. Os dados das lesões hepáticas foram avaliados pelo teste não paramétrico de Kuskal-Wallis, uma vez que não atingiram a normalidade nem mesmo após a transformação dos dados (Box-Cox ou Johnson).

Os diferentes níveis de inclusão de GB na dieta de tourinhos não alteraram o número de papilas por $\mathrm{cm}^{2}$ de parede ruminal $(\mathrm{P}=0,70)$ nem a área de superfície absortiva do rúmen $(\mathrm{P}=0,89)$. Os animais que receberam dietas com níveis mais altos de glicerina (12 e 18\%) tiveram maior índice mitótico da camada basal do epitélio ruminal $(\mathrm{P}<0,01)$. Porém, maior proliferação celular não se refletiu em ganho de altura e área das papilas $(\mathrm{P}=0,82)$ (Tab. 2). Paschoaloto (2016) avaliou o efeito da inclusão de GB em dietas de alto concentrado sobre a morfologia das papilas ruminais de bovinos confinados. Da mesma forma, foi verificada maior proliferação celular no epitélio ruminal em animais que receberam GB, porém a inclusão desse ingrediente também não alterou a morfologia papilar. O tipo de AGCC presente no conteúdo ruminal pode afetar a resposta em crescimento das células do epitélio. O propionato e o butirato parecem ser mais estimuladores do crescimento papilar que o acetato (Costa et al., 2008). Após a ingestão, o glicerol presente na GB pode ser rapidamente fermentado no rúmen e acarretar maior produção de propionato e butirato (Van Cleef et al., 2015; Defrain et al., 2004). No presente trabalho, possivelmente, maior proliferação celular no epitélio ruminal observada nos animais que receberam dietas com níveis mais altos de GB foi devido à maior produção de propionato e butirato. De acordo com Krehbiel (2008), o glicerol pode ser absorvido pela mucosa ruminal e convertido à glicose no fígado. Assim, uma parcela do glicerol oriundo da inclusão de GB da dieta pode ter sido fermentada pelos microrganismos ruminais, e outra parcela pode ter sido absorvida pela parede ruminal. Isso poderia explicar, pelo menos em parte, o porquê de a maior proliferação celular no epitélio ruminal não ter sido acompanhada por maiores dimensões papilares e área de superfície absortiva. Embora a substituição de milho por GB na dieta, em níveis de 12 e 18\%, não tenha proporcionado ganhos em dimensões papilares e de superfície absortiva no rúmen, possivelmente, maior proliferação celular no epitélio ruminal tenha refletido em maior quantidade de células metabolicamente ativas de propionato e butirato, o que é desejável do ponto de vista de integridade da mucosa ruminal e do clearance de AGCC.

Tabela 2. Índice mitótico (IM) do epitélio e morfometria de papilas do rúmen e do omaso de animais submetidos a diferentes níveis de glicerina

\begin{tabular}{|c|c|c|c|c|c|c|}
\hline \multirow{2}{*}{ Variável } & \multicolumn{4}{|c|}{ Glicerina $(\%)$} & \multirow{2}{*}{$\mathrm{P}$ valor } & \multirow{2}{*}{$\mathrm{CV}(\%)$} \\
\hline & 0 & 6 & 12 & 18 & & \\
\hline \multicolumn{7}{|l|}{ Rúmen } \\
\hline Índice mitótico $(\mathrm{x} 1000)^{1}$ & 2,77 & 3,54 & $5,13 *$ & $4,14^{*}$ & $<0,01$ & 25,1 \\
\hline Área papila & 5,56 & 5,92 & 6,06 & 6,13 & 0,82 & 14,9 \\
\hline Altura papila & 166,69 & 149,79 & 143,43 & 140,42 & 0,82 & 28,1 \\
\hline \multicolumn{7}{|l|}{ Omaso } \\
\hline Índice mitótico (x1000) & 4,22 & 4,98 & 4,70 & 4,45 & 0,43 & 31,91 \\
\hline Área da papila & 8,21 & 8,39 & 8,57 & 8,56 & 0,56 & 8,00 \\
\hline Altura da papila & 88,73 & 98,74 & 99,49 & 99,11 & 0,09 & 11,72 \\
\hline
\end{tabular}

${ }^{1}$ Regressão linear $(\mathrm{P}<0,05) .{ }^{*}$ Difere do controle $(0 \%$ glicerina) pelo teste de Dunnett a $5 \%$.

A mucosa omasal não foi alterada pela inclusão de GB em substituição ao milho integral moído, considerando que não houve efeito desse coproduto sobre o IM $(\mathrm{P}=0,43)$; a área e altura papilar $(\mathrm{P}=0,56$ e $\mathrm{P}=0,9$, respectivamente) (Tab.
2). Considerando que aproximadamente $50 \%$ do clearance dos AGCC produzidos no ruminoretículo de ruminantes adultos ocorrem por passagem com a fase fluida ruminal para $o$ omaso (Resende Júnior et al., 2006) e que $13 \%$ 
do glicerol que chega ao rúmen desaparece por passagem com a digesta (Krehbiel 2008), os dados sugerem que a inclusão de GB em níveis de até $18 \%$ da matéria seca da dieta não interfere na morfologia e capacidade de absorção pela parede do omaso.

As principais lesões observadas no fígado foram vacuolização hepatocelular, inflamação, tumefação centrolobular, congestão difusa e necrose multifocal aleatória associada a infiltrado inflamatório mononuclear. Dez animais $(22,72 \%)$ não apresentaram lesões, $19(43,18 \%)$ apresentaram lesões leves, $10(22,72 \%)$ lesões moderadas e três $(6,81 \%)$ lesões acentuadas. De acordo com Krehbiel (2008), o glicerol pode ser absorvido pela mucosa ruminal e convertido à glicose no fígado. Entretanto, não foi observada associação entre o uso dos diferentes níveis de glicerina e a ocorrência e gravidade das lesões hepáticas em tourinhos ( $\mathrm{P}>0,05)$. Parsons et al. (2009) avaliaram a inclusão de $16 \%$ de glicerol na alimentação de novilhas que recebiam dietas com $94 \%$ de concentrado e verificaram que $11,2 \%$ dos animais apresentaram abscessos hepáticos. Porém, não encontraram significância entre o aumento da inclusão do glicerol e a presença dos abscessos.

A inclusão de GB em até $18 \%$ da matéria seca da dieta não alterou a morfologia da mucosa ruminal e omasal, bem como a integridade do parênquima hepático de tourinhos em terminação. O uso desse coproduto em níveis de 12 e $18 \%$ estimulou a proliferação celular no epitélio ruminal e, possivelmente, acarretou maior atividade metabólica e capacidade de clearance de AGCC e de glicerol pela parede do rúmen.

Os autores agradecem o apoio financeiro do Conselho Nacional de Desenvolvimento Científico e Tecnológico - CNPq, da Coordenação de Aperfeiçoamento de Pessoal de Nível Superior CAPES e da Fundação de Amparo à Pesquisa do Estado de Minas Gerais - FAPEMIG.

Palavras-chave: glicerol, morfofisiologia, ruminantes

\begin{abstract}
The morphology of the ruminal and omasal mucosa and hepatic parenchyma of 44 young bulls submitted to four types of concentrates were evaluated by varying the inclusion level of crude Glycerin - CG $(0,6$, 12 and 18\%). The variables evaluated were number of ruminal papillae per $\mathrm{cm}^{2}$ of wall; area of the papillae and total absorption surface per $\mathrm{cm}^{2}$ of wall; Mitotic index - MI, height and area of ruminal and omasal papillae; and hepatic morphology. The samples processed for inclusion in paraffin and stained with Hematoxylin-Eosin. The different levels of inclusion of $C G$ in the diet did not interfere either in the number of papillae per $\mathrm{cm}^{2}$ of rumen wall $(P=0,70)$ or in the ruminal absorptive surface area $(P=0,89)$. Animals that received diets with levels 12 and $18 \%$ had higher MI of the ruminal epithelium $(P<0.01)$, but higher cell proliferation wasn't reflected in height gain and papillary area $(P=0,82)$. The omasal mucosa wasn't influenced by the inclusion of CG (MI e height gain and papillary area, $P=0,43, P=0,56$ e $P=0,9$, respectively). The inclusion of $G B$ in up to $18 \%$ of diet dry matter didn't alter the morphology of the rumen and omaso mucosa; and the integrity hepatic parenchyma.
\end{abstract}

Keywords: glycerol, morphophysiology, ruminant

\section{REFERÊNCIAS}

AZEVEDO, R.A.; MACHADO, F.S.; CAMPOS, M.M. et al. The effects of increasing amounts of milk replacer powder added to whole milk on passage rate, nutrient digestibility, ruminal development, and body composition in dairy calves. J. Dairy Sci., v.99, p.8746-8758, 2016.
COSTA, S.F.; PEREIRA, M.N.; MELO, L.Q. et al. Alterações morfológicas induzidas por butirato, propionato e lactato sobre a mucosa ruminal e a epiderme de bezerros - I Aspectos histológicos. Arq. Bras. Med. Vet. Zootec., v.60, p.1-9, 2008.

DANIEL， J.L.P.; RESENDE JÚNIOR， J.C.; CRUZ, F.J. Participação do ruminoretículo e omaso na superfície absortiva total do proventrículo de bovinos. Braz. J. Vet. Res. Anim. Sci., v.43, p.688-694, 2006. 
DEFRAIN, J.M.; HIPPEN, A.R.; KALSCHEUR, K.F. et al. Feeding glycerol to transition dairy cows: effects on blood metabolites and lactation performance. J. Dairy Sci., v.87, 4195-4206, 2004.

DONKIN, S.S. Glycerol from biodiesel production: the new corn for dairy cattle. Rev. Bras. Zootec., v.37, p.280-286, 2008.

KREHBIEL, C.R. Ruminal and physiological metabolism of glycerin. J. Anim. Sci., v.86, p.392, 2008.

LADEIRA, M.M.; CARVALHO, J.R.R.; CHIZZOTTI M.L. et al. Effect of increasing levels of glycerin on growth rate, carcass traits and liver gluconeogenesis in young bulls. Anim. Feed Sci. Tech., v.219, p.241, 2016.

PARSONS, G.L.; SHELOR, M.K.; DROUILLARD, J.S. Performance and carcass traits of finishing heifers fed crude glycerin. $J$. Anim. Sci., v.87, p.653-657, 2009.
PASCHOALOTO, J.R. Protocolos experimentais de confinamento para bovinos Nelore alimentados com dietas contendo glicerina bruta. 2016. 49f. Tese (Doutorado em Zootecnia) - Faculdade de Ciências Agrárias e Veterinárias, Universidade Estadual Paulista, Jaboticabal, S.P.

RESENDE JÚNIOR, J.C.; ALONSO, L.S.; PEREIRA, M.N. et al. Comparison of Techniques to determine the clearance of ruminal volatile fatty acids. J. Dairy Sci., v.89, p.30963106, 2006.

VAN CLEEF, E.H.C.B.; ALMEIDA, M.T.C.; PEREZ, H.L. et al. Crude glycerin changes ruminal parameters, in vitro greenhouse gas profile, and bacterial fractions of beef cattle. Livest. Sci., v.178, p.158-164, 2015. 